\title{
In vitro differentiation of human umbilical cord-derived mesenchymal stem cells into $\mathrm{CD}^{+}{ }^{+}$cells via CD34 antibody
}

\author{
Shengnan Guo ${ }^{1,2}$, Libin Guo ${ }^{1}$, Maoxiang Sun ${ }^{1,2}$, Wenyue Ma ${ }^{1,2}$, Yujia Lu ${ }^{1,2}$, Ying Liu ${ }^{1 *}$ \\ ${ }^{1}$ Department of Stem Cell Clinical Application Central, Siping Hospital Affiliated to China Medical University, Siping, China \\ ${ }^{2}$ Tuhua Bioengineering Company Ltd., Siping, China \\ Email: ${ }^{* 1 y 3641829 @ 163 . c o m}$
}

Received 10 June 2013; revised 15 July 2013; accepted 30 July 2013

Copyright (C) 2013 Shengnan Guo et al. This is an open access article distributed under the Creative Commons Attribution License, which permits unrestricted use, distribution, and reproduction in any medium, provided the original work is properly cited.

\begin{abstract}
$\mathrm{CD}^{+} 4^{+}$cells differentiated from mesenchymal stem cells (MSCs) have a strong biological function in cardiovascular regeneration. However, the molecular mechanisms of and the methods to improve the $\mathrm{CD}_{3}{ }^{+}$ cell differentiation from MSCs, especially from human MSCs (hUC-MSCs) are still unclear. In the current study, the effect of CD34 antibody on the CD34 ${ }^{+}$ cell differentiation from human umbilical cord (UC)derived MSCs (hUC-MSCs) is determined. The results have demonstrated that the expression of cd34 protein is significantly increased in hUC-MSCs treated with CD34 antibody. In addition, the cell proliferation is increased in hUC-MSCs after treatment with CD34 antibody. Moreover, the expression of PI3K, AKT, p-AKT proteins, which are signaling molecules related to stem cell differentiation, is increased by CD34 antibody. The results suggest that CD34 antibody could promote the differentiation of hUC-MSCs into $\mathrm{CD}^{+} 4^{+}$cells and PI3K/AKT may be involved in this important process.
\end{abstract}

Keywords: Differentiation; Human Umbilical Cord-Derived Mesenchymal Stem Cells; CD34 ${ }^{+}$Cells

\section{INTRODUCTION}

$\mathrm{CD}^{+} 4^{+}$mesenchymal stem cell (MSC) transplantation has received growing attention as a promising treatment for cardiovascular diseases [1,2]. MSCs, being a heterogeneous stromal cell population, having the capacity to self-renew as well as to differentiate into a variety of terminally differentiated cells, including adipocytes, chondrocytes, endothelial cells, and osteocytes [3-5]. MSCs also

\footnotetext{
"Corresponding author.
}

have the capacity to home in the sites of vascular injury, to engraft into damaged blood vessels, to differentiate into vascular cells, and to exert a paracrine effect by the local release of vascular growth factors and cytokines $[4,6,7]$. However, the molecular mechanisms of and the methods to improve the $\mathrm{CD} 34^{+}$cell differentiation from MSCs, especially from human MSCs (hUC-MSCs) are still unclear.

CD34 antibody has been widely used as a molecular tool to separate a sub-group of MSCs (CD34 ${ }^{+}$-MSCs) for stem cell studies and for stem cell therapeutic applications. However, the potential biological functions of CD34 antibody in CD34 expression and CD34 ${ }^{+}$cell differentiation of MSCs are currently unknown. In this study, we are trying to determine the effect of the CD34 antibody on the expression of CD34 in cultured human umbilical cord (UC)-derived MSCs (hUC-MSCs) and the potential mechanisms involved.

\section{MATERIALS AND METHODS}

\subsection{Harvesting of UC}

Five human UC samples were collected from the mothers, in accordance with the ethical committee of Institute of Siping Central Hospital. Informed consent was obtained from all subjects. All studies and laboratory procedures were carried out in the Siping Central Hospital. The sections of umbilical cords were internally washed with phosphatebuffered saline (PBS) containing $300 \mathrm{U} / \mathrm{ml}$ penicillin and $300 \mathrm{ug} / \mathrm{ml}$ streptomycin (Gibco, Grand Island, NY), and immediately immersed in Dulbecco's modified Eagle's medium-low glucose (DMEM-LG; Gibco) supplemented with $10 \%$ fetal bovine serum (FBS; Gibco), 300 $\mathrm{U} / \mathrm{ml}$ penicillin, and $300 \mathrm{ug} / \mathrm{ml}$ streptomycin. All samples were processed within $12-15$ hours after collection. 


\subsection{Isolation and Culture of Adherent Cells from UC}

As described in our previous study [8], UCs were filled with $0.1 \%$ collagenase (Sigma-Aldrich, St. Louis) in PBS and incubated at $37^{\circ} \mathrm{C}$ for $20 \mathrm{~min}$. Each UC was washed with proliferation medium, and the detached cells were harvested after gentle massage of the UC. Cells were centrifuged at $300 \mathrm{~g}$ for $10 \mathrm{~min}$, resuspended in proliferation medium, and seeded in $75-\mathrm{cm}^{2}$ flasks at a density of $5 \times 10^{7}$ cells per $\mathrm{ml}$. After $24 \mathrm{~h}$ of incubation, nonadherent cells were removed, and culture medium was added with CD34 antibody $(0.1 \mathrm{ug} / \mathrm{ml})$ and replaced every 2 days. Adherent cells were cultured until they reached $80 \%$ - $90 \%$ confluence.

\subsection{Flow Cytometry}

The hematopoietic lineage marker CD45, human leucocyte antigen HLA-DR, the cell-surface markers of endothelial progenitor cells CD31 and CD90, were determined by flow cytometry. In this experiment, the adherent cells were incubated for $2 \mathrm{~h}$ at $37^{\circ} \mathrm{C}$ with the rabbit antihuman fluorophore-conjugated primary antibodies (all diluted 1:1000 in 0.01 M PBS; all from Becton Dickinson, Franklin Lakes, NJ, USA) for direct immunofluorescence staining. A total of 10,000 labeled cells were analyzed using a Becton Dickinson LSRFortessa ${ }^{\mathrm{TM}}$ Cell Analyzer with the Becton Dickinson FACSDiva ${ }^{\mathrm{TM}}$ software version 6.0 (Becton Dickinson Biosciences, San Jose, CA, USA).

\subsection{Cell Proliferation Assay}

hUC-MSCs were incubated with CD34 antibody (0.01 $\mu \mathrm{mol} / \mathrm{l}, 0.1 \mu \mathrm{mol} / 1$ or $1 \mu \mathrm{mol} / \mathrm{l})$ for $96 \mathrm{~h}$. The effects of CD34 antibody on proliferation were assessed by cell counting. hUC-MSCs without CD34 antibody treatment were selected as a control group. Cell counts were expressed as a percentage of the control.

\subsection{Immunofluorescence Staining.}

hUC-MSCs were incubated with CD34 antibody $(0.01$ $\mu \mathrm{mol} / \mathrm{l}, 0.1 \mu \mathrm{mol} / 1$ or $1 \mu \mathrm{mol} / \mathrm{l}$, defined as $\mathrm{A}, \mathrm{B}$ and $\mathrm{C}$ group) for $7 \mathrm{~d}$ or $14 \mathrm{~d}$. hUC-MSCs without CD34 antibody treatment were used as a control group. Adherent cells were fixed with $4 \%$ cold paraformaldehyde (Sigma) for 15 min and permeabilized with $0.1 \%$ Triton X-100 (Sigma) for $10 \mathrm{~min}$. After washing with PBS, cells were blocked with $3 \%$ bovine serum albumin (BSA, Sigma) for $30 \mathrm{~min}$, followed by incubating overnight at $4^{\circ} \mathrm{C}$ with mouse anti-human primary antibody against CD34 (1:200, Abcam), or rabbit anti-human primary antibody against CD105 (1:200, Abcam). The FITC-labeled secondary antibody (1:100; goat polyclonal to rabbit IgG; Abcam) and
PRITC-labeled secondary antibody $(1: 100$; goat polyclonal to mouse IgG; Abcam) were then added and incubated for $1 \mathrm{~h}$ at $37^{\circ} \mathrm{C}$ temperature. Cells were washed three times with PBS and counter-stained with DAPI (4',6-diamidino-2-phenylindole) nuclear dye. The immunofluorescence staining was observed using Leica DM5000 B fluorescence microscope.

\subsection{Western Blot Analysis}

hUC-MSCs were incubated with CD34 antibody $(0.01$ $\mu \mathrm{mol} / 1,0.1 \mu \mathrm{mol} / 1$ or $1 \mu \mathrm{mol} / \mathrm{l}$ ) for $7 \mathrm{~d}$ or $14 \mathrm{~d}$. hUCMSCs without CD34 antibody treatment were used as a control group. Homogenates were prepared from these MSCs using radioimmunoprecipitation assay buffer as described previously [8]. Equal amounts of protein (20 $40 \mu \mathrm{g}$ ) were added and separated on a 14\% Tris-glycine gel, transferred to a polyvinylidene difluoride membrane, and incubated with a PI3K, AKT or a p-AKT primary antibody (Amyjet Scientific Inc, Wuhan, China) at a dilution of 1:500. The membranes were incubated with an anti-rabbit horseradish peroxidase antibody and developed by enhanced chemiluminescence. The blots were then treated with a protein stripping buffer, reblocked with a blocking agent, and then immunostained with an antibody against human $\beta$-actin (Santa Cruz Biotechnology, Inc., Santa Cruz, CA) as the loading controls.

\subsection{Statistical Analysis}

All data are expressed as mean \pm SEM (standard error of the mean). All the experiments were repeated independently at least 3 times. Data were analyzed using analysis of variance followed by Student's $t$ test when only two groups were studied, taking $p<0.05$ as significant.

\section{RESULTS}

\subsection{Isolation and Culture of Adherent Cells from UC}

Similar to our previous studies [8], primary adherent cultures were generated from all UCs samples, with cells displaying a mesenchymal stem cell (MSC)-like phenoltype. After 4 days in culture the cells formed colonies, reaching confluence after $10-14$ days. Most of the cells were spindle-shaped, resembling fibroblasts. After the second passage, adherent cells constituted homogeneous cell layers with an MSC-like phenotype. The number of adherent cells from the UCs decreased slightly after freezing and thawing, and the remaining viable cells were successfully expanded on consecutive days (data not shown).

\subsection{Immunophenotype}

Very few of the adherent cells derived from the UC sam- 
ples had haematopoietic lineage markers CD45, endothelial markers (CD31) and HLA-DR (HLA-class II) on the cell surface, as assessed by flow cytometry. The majority of the cells presented high levels of CD90 protein on the cell surface. In comparison with the fibroblast control, no obvious difference in the levels of surface antigens could be observed, which were similar to our previous studies [8].

\subsection{Cell Proliferation Assay}

The effect of CD34 antibody on cell proliferation was assessed by cell counting. Compare with the control group, hUC-MSCs incubated with CD34 antibody $(0.01 \mu \mathrm{mol} / 1$, $0.1 \mu \mathrm{mol} / 1$ or $1 \mu \mathrm{mol} / \mathrm{l}$ ) for $96 \mathrm{~h}$ proliferated at $21 \%, 53 \%$, 28\% separately (Table 1 ).

\subsection{Immunohistological Findings}

To further study the biological characteristics of the differentiated $\mathrm{CD} 34^{+}$cells from hUC-MSCs, we determined the expression of CD34 and CD105 on the cells' surface at 7, 14 days after treatment with CD34 antibody (Figure 1). CD34 expression was identified by red fluorescence, whereas CD105 expression was displayed by green fluorescence. Many green cells were observed in every time point. The numbers of red cells in these slices were significantly higher $(\mathrm{P}<0.05)$ than green cells. In addition, as shown in Figures 1(b) and (c), and F-H, we observed small, solitary yellow fluorescence which indicated that cells treated with CD34 antibody could co-express CD34 and CD105 protein. More cells express CD34 protein (red fluorescence) than CD105 protein (green fluorescence) in $\mathrm{C}$ group at $14 \mathrm{~d}$, which suggested the loss of CD105 protein.

\subsection{Expression of AKT Protein}

PI3K, AKT, p-AKT proteins were expressed in the differentiation process of hUC-MSCs incubated with CD34 antibody $(0.01 \mu \mathrm{mol} / 1,0.1 \mu \mathrm{mol} / 1$ or $1 \mu \mathrm{mol} / 1)$ for $7 \mathrm{~d}$ and $14 \mathrm{~d}$. Compare with the control group, hUC-MSCs were incubated with CD34 antibody $(0.01 \mu \mathrm{mol} / 1,0.1$ $\mu \mathrm{mol} / 1$ or $1 \mu \mathrm{mol} / \mathrm{l}$ ) for $7 \mathrm{~d}, \mathrm{PI} 3 \mathrm{~K}$ protein increased by 7\%, 23\%, 43\% separately; AKT and p-AKT were similar

Table 1. hUC-MSCs were incubated with CD34 antibody (0.01 $\mu \mathrm{mol} / 1,0.1 \mu \mathrm{mol} / 1$ or $1 \mu \mathrm{mol} / \mathrm{l})$ for $96 \mathrm{~h}$. The effects of CD34 antibody on proliferation were assessed by cell counting. hUCMSCs without CD34 antibody treatment were selected as a control group. Cell counts were expressed as a percentage of the control. Compared with the control group, hUC-MSCs were incubated with CD34 antibody $(0.1 \mu \mathrm{mol} / 1$ or $1 \mu \mathrm{mol} / \mathrm{l})$ for $96 \mathrm{~h}$ proliferated $48.6 \%, 28.3 \%$ separately. ${ }^{*} \mathrm{P}<0.05$.

\begin{tabular}{cccc} 
Control & $0.01 \mu \mathrm{mol} / 1$ & $0.1 \mu \mathrm{mol} / 1$ & $1 \mu \mathrm{mol} / 1$ \\
\hline $0.45 \pm 0.02$ & $0.42 \pm 0.01$ & $0.83 \pm 0.03^{*}$ & $0.59 \pm 0.02$ \\
\hline
\end{tabular}

to PI3K protein express (see Figures 2(a) and (b)). At 14 $\mathrm{d}$, the expression of PI3K, AKT, p-AKT proteins was higher than that at $7 \mathrm{~d}$ (see Figures 2(a) and (b)).

\section{DISCUSSION}

In the present study, we have demonstrated for the first time that CD34 antibody could promote hUC-MSCs to co-express CD34 and CD105 proteins. While agreeing with the previously report $[9,10]$, during this process, we have observed the cultured cells express CD105 (green staining in Figure 1) at the early phase, and express CD34 (red staining in Figure 1) in the following days.

MSCs are a heterogeneous stromal cell population, and cells display some phenotypic and functional characteristics of endothelial cells. In our previous study, changes in hUC-MSCs have been detected utilizing multiple culture methods and we have observed the osteodifferention of hUC-MSCs [8]. Changes in hUC-MSCs are coupled with human maladies [11,12]. However, these cells require laborious and time intensive culture techniques. Until now, the differentiation of hUC-MSCs remains undefined, in part because there is not a consensus definition by cell surface antigen expression, such as CD34 and CD105. CD34 has been used as biomarkers in endothelial progenitor cells (EPCs) as well as angiogenesis therapies [13,14]. CD105 and CD34 have been found at the sites of blood vessel formation $[15,16]$. In this study, the expression of CD34 and CD105 in different phase suggests that CD34 antibody could promote the hUC-MSC differentiation into $\mathrm{CD} 34^{+}$cells.

Multiple signaling pathways are involved in the differentiation of MSCs. Akt is known to be part of a prosurvival pathway and the phosphorylation at Thr308 is required for Akt activation [17,18]. In the current study, we have found that PI 3-kinase and phospho-Akt (Thr308) are elevated in CD34 antibody-treated hUC-MSCs compared with the control group. However, the effect of CD34 antibody-mediated up-regulation of CD34 expression is reduced when the concentration of the CD34 antibody reaches at 1 umol/l. The result suggests that maximal effect of CD34 antibody on the CD34 expression may occur at 0.1 umol/1. These observations were complied with survival of hUC-MSCs in $96 \mathrm{~h}$ at different CD34 antibody concentrations. It is still unclear why Akt (Thr308) is changed, since this would promote but not inhibit apoptosis. However, other phosphorylation sites or downstream effectors may be involved in the prosurvival and differentiated effect of hUC-MSCs-conditioned media.

Limitations of this current study were: 1) the lack of cell proliferation assay continuous data, which could have confirmed a direct positive effect of CD34 antibody on hUC-MSC differentiation capability; 2) The lack of 

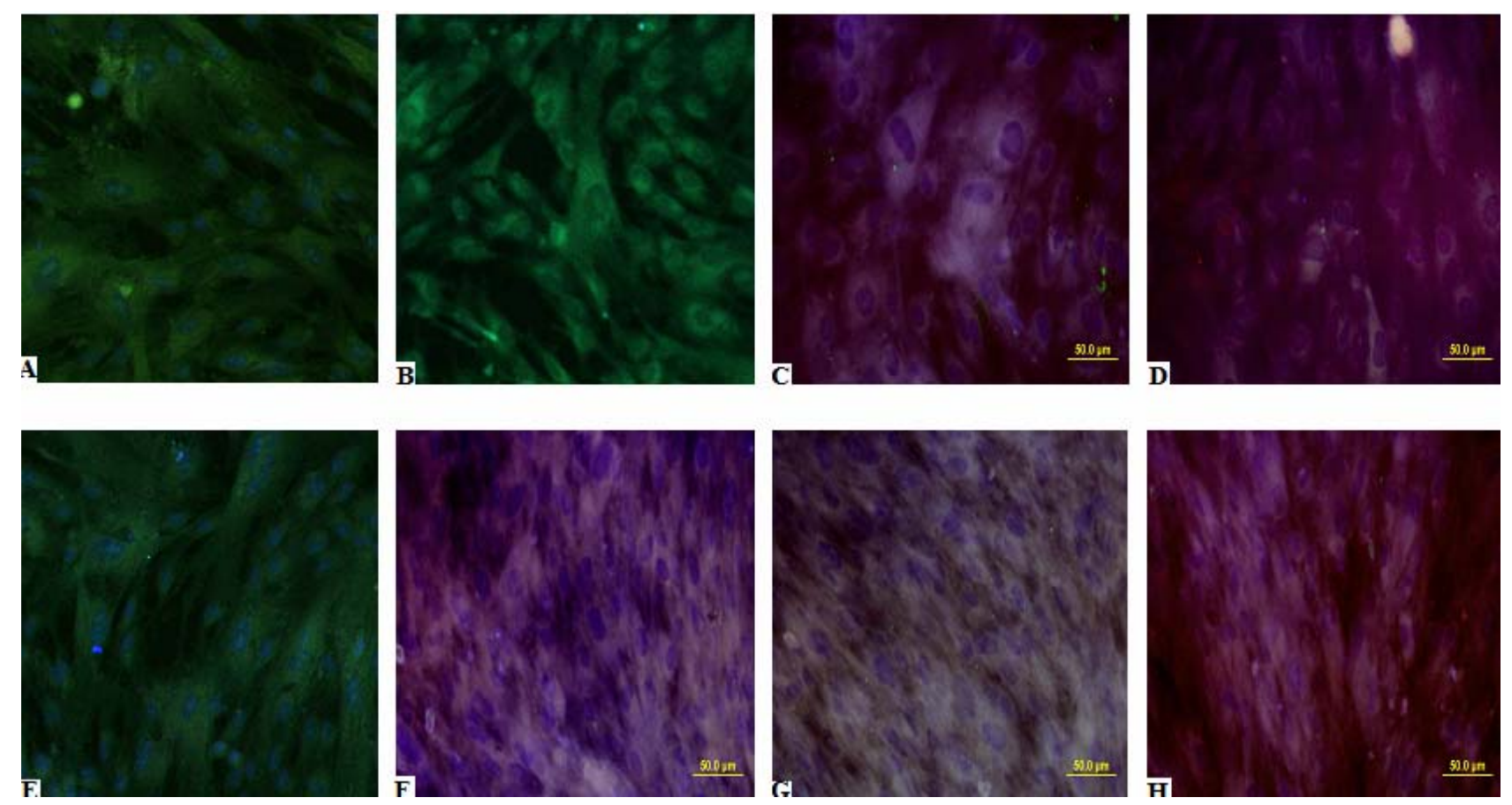

(a)

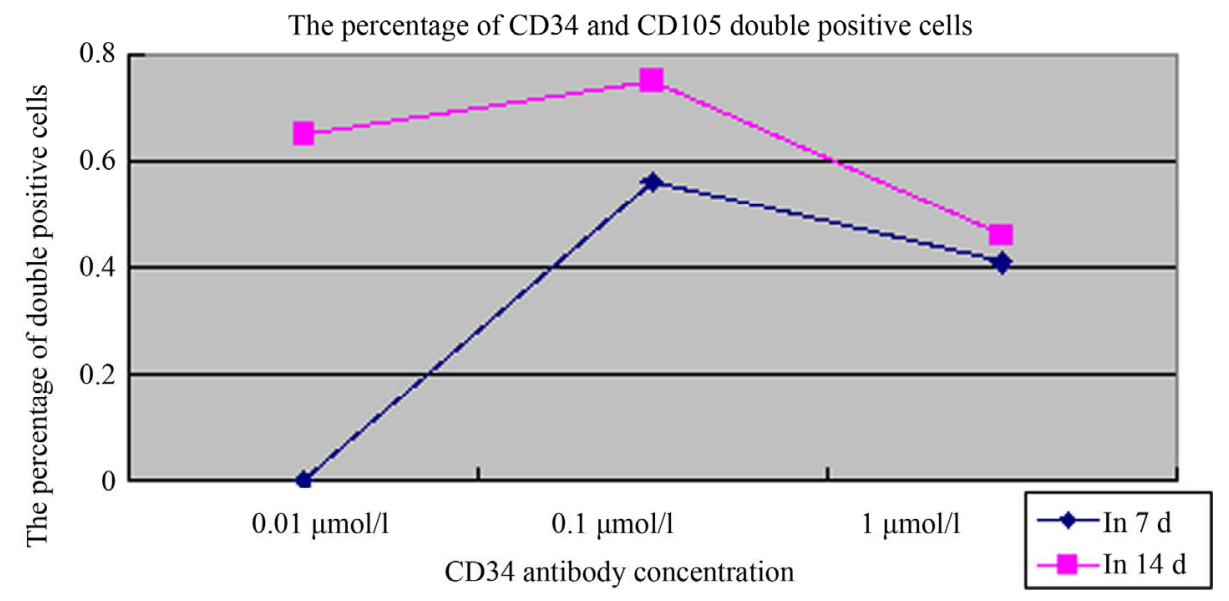

(b)

Figure 1. CD34 and CD105 double positive cells immunofluorescence findings. (a) Immunofluorescence Findings (CD34 protein: red fluorescence; CD105 protein: green fluorescence). A. CD105 protein expression of hUC-MSCs incubated without CD34 antibody at $7 \mathrm{~d}$; B. CD105 protein expression of hUC-MSCs incubated with $0.01 \mu \mathrm{mol} / 1 \mathrm{CD} 34$ antibody at $7 \mathrm{~d}$; C. CD105 and CD34 protein expression of hUC-MSCs incubated with $0.1 \mu \mathrm{mol} / 1 \mathrm{CD} 34$ antibody at $7 \mathrm{~d}$; D. CD105 and CD34 protein expression of hUC-MSCs incubated with $1 \mu \mathrm{mol} / \mathrm{l} \mathrm{CD} 34$ antibody at $7 \mathrm{~d}$; E. CD105 protein expression of hUC-MSCs incubated without CD34 antibody at 14d; F. CD105 and CD34 protein expression of hUC-MSCs incubated with $0.01 \mu$ mol/1 CD34 antibody at $14 \mathrm{~d}$; G. CD105 and CD34 protein expression of hUC-MSCs incubated with $0.1 \mu \mathrm{mol} / 1 \mathrm{CD} 34$ antibody at $14 \mathrm{~d}$; H. CD105 and CD34 protein expression of hUC-MSCs incubated with $1 \mu \mathrm{mol} / 1$ CD34 antibody at $14 \mathrm{~d}$; (b) The percentage of CD34 and CD105 double positive cells analysis. The data were shown as the percentage of CD34 and CD105 double positive cells of the total cells.

telomerase activity analysis, which could have confirmed maturation of cells; 3) The lack of the necessary functional assays to verify these cells function in vessel formation in vivo. Further controlled basically experiments will be required to confirm our preliminary findings and to elucidate the full characterization and mechanistic determination involved in improving hUC-MSCs differen- tiation, following treated with CD34 antibody.

In summary, our work demonstrated a new method to promote hUC-MSC differentiation via CD34 antibody. Administration of CD34 antibody is able to accelerate the differentiation of hUC-MSCs into $\mathrm{CD} 34^{+}$cells and AKT may play a role in this process. These findings reinforce our previous observation on the importance of 


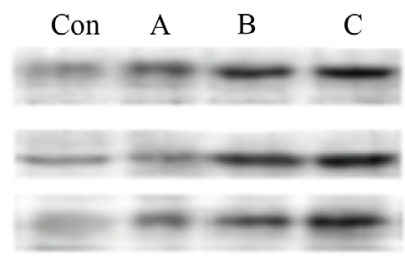

(a1)

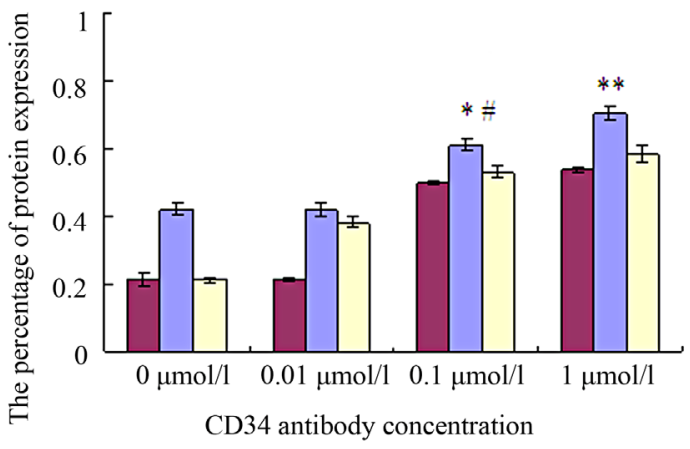

(b1)

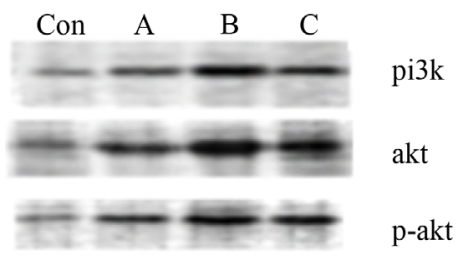

(a2)

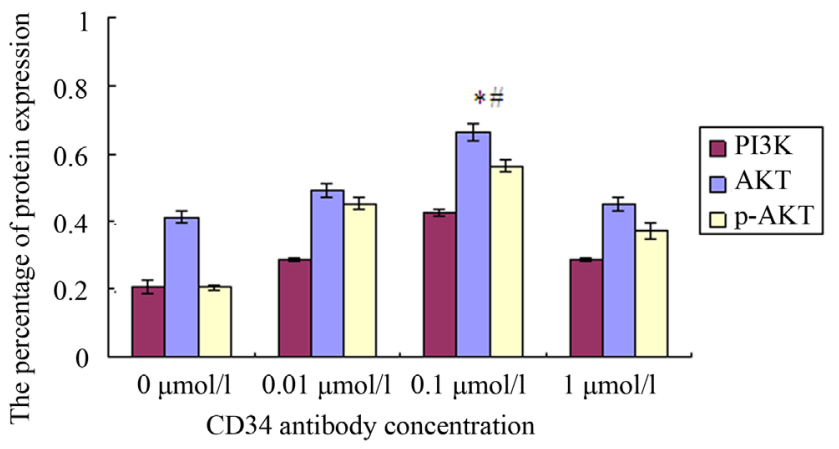

(b2)

Figure 2. Expression of protein. (a) Expression of protein. PI3K, AKT, p-AKT protein expressed in the differentiation phase of hUC-MSCs incubated with CD34 antibody $(0.01 \mu \mathrm{mol} / 1,0.1 \mu \mathrm{mol} / 1$ or $1 \mu \mathrm{mol} / \mathrm{l})$ as A, B and C group for $7 \mathrm{~d}$ and $14 \mathrm{~d}$ separately; con: control group. (a1) Expression of protein in $7 \mathrm{~d}$; (a2) Expression of protein in $14 \mathrm{~d}$. (b) Expression of protein analysis. (b1) Expression of protein analysis in $7 \mathrm{~d}$. Compared with the control group, hUC-MSCs incubated with CD34 antibody $(0.01 \mu \mathrm{mol} / 1,0.1$ $\mu \mathrm{mol} / 1$ or $1 \mu \mathrm{mol} / 1$ ) for $7 \mathrm{~d}$, PI3K protein expression increased $7 \%, 23 \%, 43 \%$ separately; AKT and p-AKT protein expression were similar to PI3K protein express; (b2) Expression of protein analysis in $14 \mathrm{~d}$. Compared with the control group, hUC-MSCs incubated with CD34 antibody $(0.01 \mu \mathrm{mol} / 1,0.1 \mu \mathrm{mol} / 1$ or $1 \mu \mathrm{mol} / 1)$ for $14 \mathrm{~d}$, PI3K protein expression increased $24 \%$, $46 \%$ in $\mathrm{A}$, and B groups separately; Compared with the B group, PI3K protein expression decreased $26 \%$ in C group. ${ }^{*} \mathrm{p}<0.05 ;{ }^{* *} \mathrm{p}<0.01 ;{ }^{\#} \mathrm{p}<0.05$.

hUC-MSCs for research and future therapeutic use.

\section{REFERENCES}

[1] Qiu, X., Sun, C., Yu, W., Lin, H., Sun, Z., Chen, Y., Wang, R. and Dai, Y. (2012) Combined strategy of mesenchymal stem cell injection with vascular endothelial growth factor gene therapy for the treatment of diabetes-associated erectile dysfunction. Journal of Andrology, 33, 3744. doi:10.2164/jandrol.110.012666

[2] Radhakrishnan, V., Muthurangan, M., May, A.-N., Balamuthu, K., Abdullah, A., Nehad, M.A. (2012) In vitro differentiation of human skin-derived multipotent stromal cells into putative endothelial-like cells. BMC Developmental Biology, 12, 7. doi:10.1186/1471-213X-12-7

[3] Uccelli, A., Moretta, L. and Pistoia, V. (2008) Mesenchymal stem cells in health and disease. Nature Reviews Immunology, 8, 726-736. doi:10.1038/nri2395

[4] Oswald, J., Boxberger, S., Jorgensen, B., Feldmann, S., Ehninger, G., Bornhauser, M. and Werner, C. (2004) Mesenchymal stem cells can be differentiated into endothelial cells in vitro. Stem Cells, 22, 377-384. doi:10.1634/stemcells.22-3-377

[5] Pittenger, M.F., Mackay, A.M., Beck, S.C., Jaiswal, R.K., Douglas, R., Mosca, J.D., Moorman, M.A., Simonetti, D.W., Craig, S. and Marshak, D.R. (1999) Multilineage potential of adult human mesenchymal stem cells. Science, 284, 143-147. doi:10.1126/science.284.5411.143

[6] Lian, Q., Zhang, Y., Zhang, J., Zhang, H.K., Wu, X., Lam,
F.F., Kang, S., Xia, J.C., Lai, W.H., Au, K.W., Chow, Y.Y., Siu, C.W., Lee, C.N. and Tse, H.F. (2010) Functional mesenchymal stem cells derived from human induced pluripotent stem cells attenuate limb ischemia in mice. Circulation, 121, 1113-1123. doi:10.1161/CIRCULATIONAHA.109.898312

[7] Liu, Z.J., Zhuge, Y. and Velazquez, O.C. (2009) Trafcking and differentiation of mesenchymalfi stem cells. Journal of Cellular Biochemistry, 106, 984-991. doi:10.1002/jcb.22091

[8] Qu, Z.G., Guo, L.B., Fang, G.J., Cui, Z.H., Guo, S.N. and Liu, Y. (2012) Biological characteristics and effect of human umbilical cord mesenchymal stem cells (hUCMSCs) grafting with blood plasma on bone regeneration in rats. Cell Biochemistry and Biophysics, 63, 171-181. doi:10.1007/s12013-012-9354-1

[9] Timmermans, F., Van Hauwermeiren, F., De Smedt, M., Raedt, R., Plasschaert, F., De Buyzere, M.L., Gillebert, T.C., Plum, J. and Vandekerckhove, B. (2007) Endothelial outgrowth cells are not derived from CD133+ cells or CD45+ hematopoietic precursors. Arteriosclerosis, Thrombosis, and Vascular Biology, 7, 1572-1579. doi:10.1161/ATVBAHA.107.144972

[10] Zhang, Y., Fisher, N., Newey, S.E., Smythe, J., Tatton, L., Tsaknakis, G., Forde, S.P., Carpenter, L., Athanassopoulos, T., Hale, S.J., Ferguson, D.J., Tyler, M.P. and Watt, S.M. (2009) The impact of proliferative potential of umbilical cord-derived endothelial progenitor cells and hypoxia on vascular tubule formation in vitro. Stem Cells and Development, 18, 359-375. 
doi:10.1089/scd.2008.0071

[11] Wu, K.H., Sheu, J.N., Wu, H.P., Tsai, C., Sieber, M., Peng, C.T. and Chao, Y.H. (2013) Cotransplantation of umbilical cord-derived mesenchymal stem cells promote hematopoietic engraftment in cord blood transplantation: A pilot study. Transplantation, 95, 773-777. doi:10.1097/TP.0b013e31827a93dd

[12] Fan, C.G., Zhang, Q.J. and Zhou, J.R. (2011) Therapeutic potentials of mesenchymal stem cells derived from human umbilical cord. Stem Cells and Development, 7, 195207. doi:10.1007/s12015-010-9168-8

[13] Bayat, H., Fathi, F., Peyrovi, H. and Mowla, S.J. (2013) Evaluating the expression of self-renewal genes in human endothelial progenitor cells. Cell Journal, 14, 298-305.

[14] Cheng, C.C., Chang, S.J., Chueh, Y.N., Huang, T.S., Huang, P.H., Cheng, S.M., Tsai, T.N., Chen, J.W. and Wang, H.W. (2013) Distinct angiogenesis roles and surface markers of early and late endothelial progenitor cells revealed by functional group analyses. BMC Genomics, 15, 14-182.

[15] Stuart, J., Smith, Hanna, T., Jennifer, H.W., Donald, C.M., James, L., Beth, C. and Richard, G.G. (2012) CD105 (Endoglin) exerts prognostic effects via its role in the micro- vascular niche of paediatric high grade glioma. Acta Neuropathologica, 124, 99-110. doi:10.1007/s00401-012-0952-1

[16] Jason, D.R., Rajendra, S.-M., Matthew, P.B., Steven, M.J., Lesley, D., Deepak, A.R., Tai, Y., Tamar, L.M., Ani, N., Brooks, U., Narutoshi, H., Toshiharu, S., Saltzman, W.M., Edward, S., Themis, R.K., Jordan, S.P., Christopher, K.B. (2010) Tissue-engineered vascular grafts transform into mature blood vessels via an inflammation-mediated process of vascular remodeling. Proceedings of the National Academy of Sciences of the USA, 107, 4669-4674.

[17] Bellacosa, A., Kumar, C.C., Di Cristofano, A. and Testa, J.R. (2005) Activation of AKT kinases in cancer: Implications for therapeutic targeting. Advanced Cancer Research, 94, 29-86. doi:10.1016/S0065-230X(05)94002-5

[18] Boomsma, R.A. and Geenen, D.L. (2012) Mesenchymal stem cells secrete multiple cytokines that promote angiogenesis and have contrasting effects on chemotaxis and apoptosis. PLoS One, 7, e35685. doi:10.1371/journal.pone.0035685 